Supporting information

\title{
Roles of Interlayer Diffusion and Confinements in Manipulating Microstructural Evolutions in Multilayer Assembled Polyvinylidene Fluoride/Poly(methyl methacrylate) Films for Tunable Dielectric and Piezoelectric Performances
}

Wei Zhao a, Mengxia Zhang ${ }^{\mathrm{a}}$, Huagui Zhang ${ }^{\mathrm{b}}$, Jiabin Shen ${ }^{\mathrm{c}}$, Bo Lu ${ }^{\mathrm{a},}$, Binbin Dong ${ }^{\mathrm{a}}$, Chuntai Liu ${ }^{\mathrm{a}}$, Abderrahim Maazouz ${ }^{\mathrm{d}, \mathrm{e}}$, Khalid Lamnawar ${ }^{\mathrm{b}, \mathrm{d}}$

${ }^{a}$ Key Laboratory of Materials Processing and Mold (Ministry of Education), National Engineering Research Center for Advanced Polymer Processing Technology, Zhengzhou University, Zhengzhou 450002, China

${ }^{b}$ College of Chemistry and Materials Science, Fujian Key Laboratory of Polymer Science, Fujian Normal University, Fuzhou 350007, China

${ }^{c}$ State Key Laboratory of Polymer Materials Engineering, Polymer Research Institute of Sichuan University, Chengdu 610065, China

${ }^{d}$ Université de Lyon, CNRS, UMR 5223, Ingénierie des Matériaux Polymères, INSA Lyon, F-69621, Villeurbanne, France

${ }^{e}$ Hassan II Academy of Science and Technology, 10100 Rabat, Morocco

* Corresponding author:

bolu@zzu.edu.cn (B. Lu) 
Table S1. Theoretical layer thicknesses of coextruded PVDF/PMMA multilayer films.

\begin{tabular}{|c|c|c|c|c|c|}
\hline $\begin{array}{c}\text { no. of } \\
\text { multipliers (n) }\end{array}$ & $\begin{array}{c}\text { no. of } \\
\text { theoretical } \\
\text { layers }\end{array}$ & $\begin{array}{c}\text { PVDF/PMMA } \\
\text { composition (v/v) }\end{array}$ & $\begin{array}{l}\text { Total film } \\
\text { thickness } \\
(\mu \mathrm{m})\end{array}$ & $\begin{array}{c}\text { PVDF } \\
\text { thickness } \\
(\mu \mathrm{m})\end{array}$ & $\begin{array}{c}\text { PMMA } \\
\text { Thickness } \\
\quad(\mu \mathrm{m})\end{array}$ \\
\hline \multirow{3}{*}{0} & \multirow{3}{*}{$2 \mathrm{~L}$} & $(25 / 75)$ & 30.27 & 7.57 & 22.70 \\
\hline & & $(50 / 50)$ & 27.15 & 13.58 & 13.58 \\
\hline & & $(75 / 25)$ & 45.27 & 33.95 & 11.32 \\
\hline \multirow{3}{*}{2} & \multirow{3}{*}{$8 \mathrm{~L}$} & $(25 / 75)$ & 44.32 & 2.77 & 8.31 \\
\hline & & $(50 / 50)$ & 34.52 & 4.31 & 4.31 \\
\hline & & $(75 / 25)$ & 37.01 & 6.95 & 2.32 \\
\hline \multirow{3}{*}{4} & \multirow{3}{*}{$32 \mathrm{~L}$} & $(25 / 75)$ & 36.15 & 0.56 & 1.69 \\
\hline & & $(50 / 50)$ & 46.48 & 1.45 & 1.45 \\
\hline & & $(75 / 25)$ & 17.73 & 0.83 & 0.28 \\
\hline \multirow{3}{*}{7} & \multirow{3}{*}{$256 \mathrm{~L}$} & $(25 / 75)$ & 22.54 & 0.04 & 0.13 \\
\hline & & $(50 / 50)$ & 32.58 & 0.13 & 0.13 \\
\hline & & $(75 / 25)$ & 20.59 & 0.12 & 0.04 \\
\hline \multirow{3}{*}{10} & \multirow{3}{*}{ 2048L } & $(25 / 75)$ & 56.49 & 0.014 & 0.04 \\
\hline & & $(50 / 50)$ & 28.61 & 0.014 & 0.014 \\
\hline & & $(75 / 25)$ & 16.89 & 0.012 & 0.004 \\
\hline
\end{tabular}

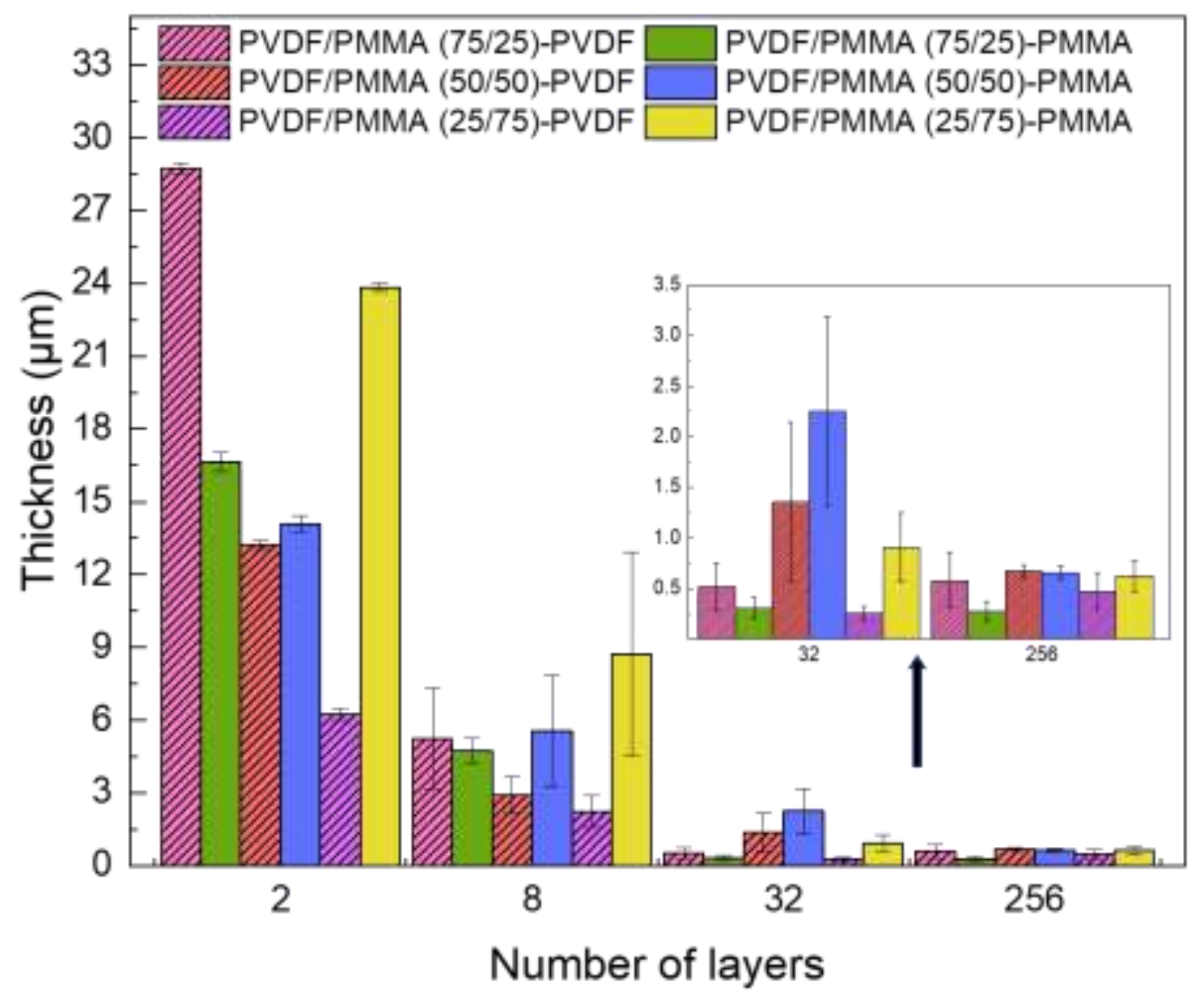

Figure S1. Statistical layer thicknesses determined by AFM analysis for PVDF/PMMA films. 


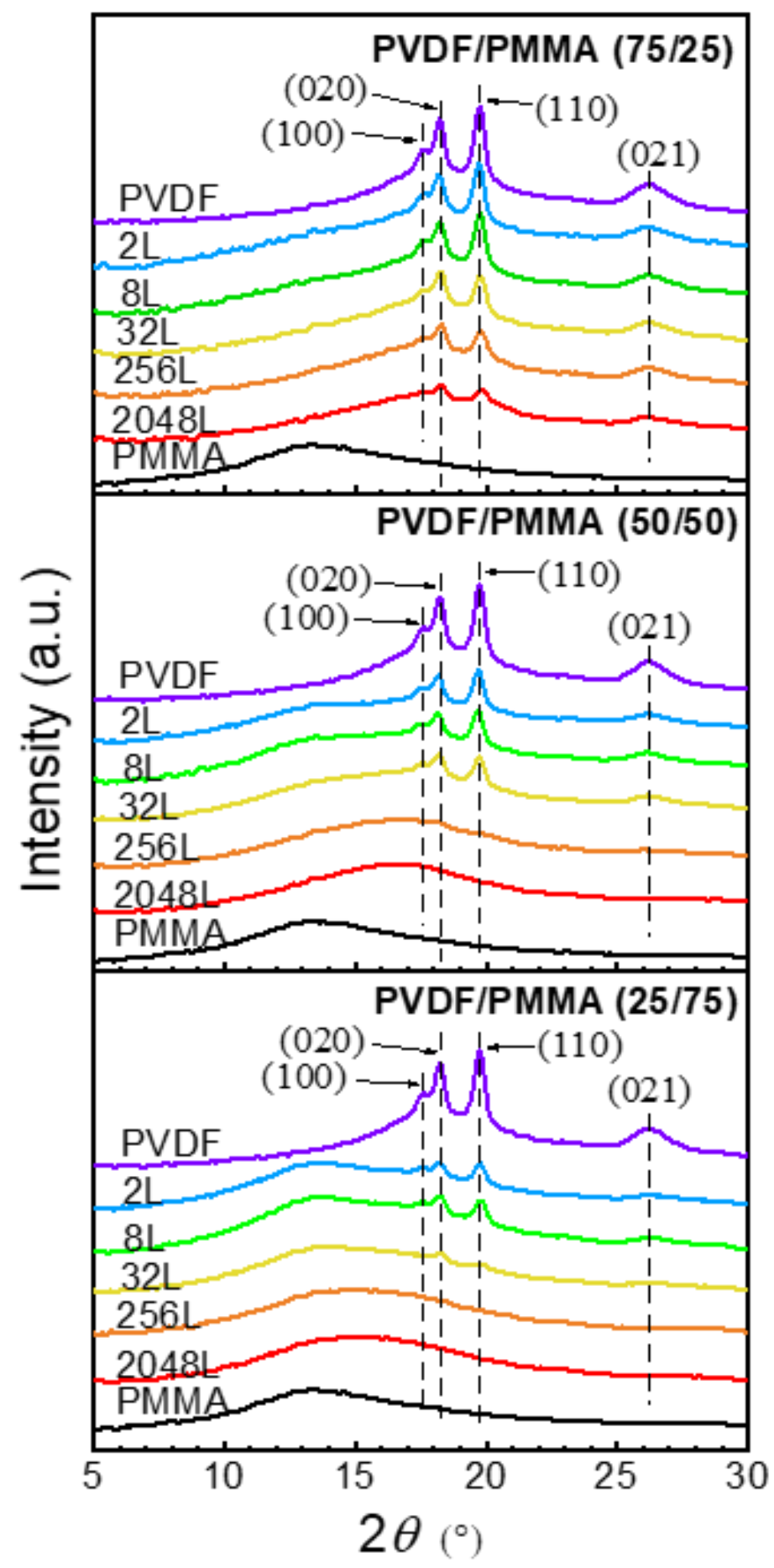

Figure S2. WAXD curves integrated from the 2D patterns for PVDF/PMMA films with varying compositions. 

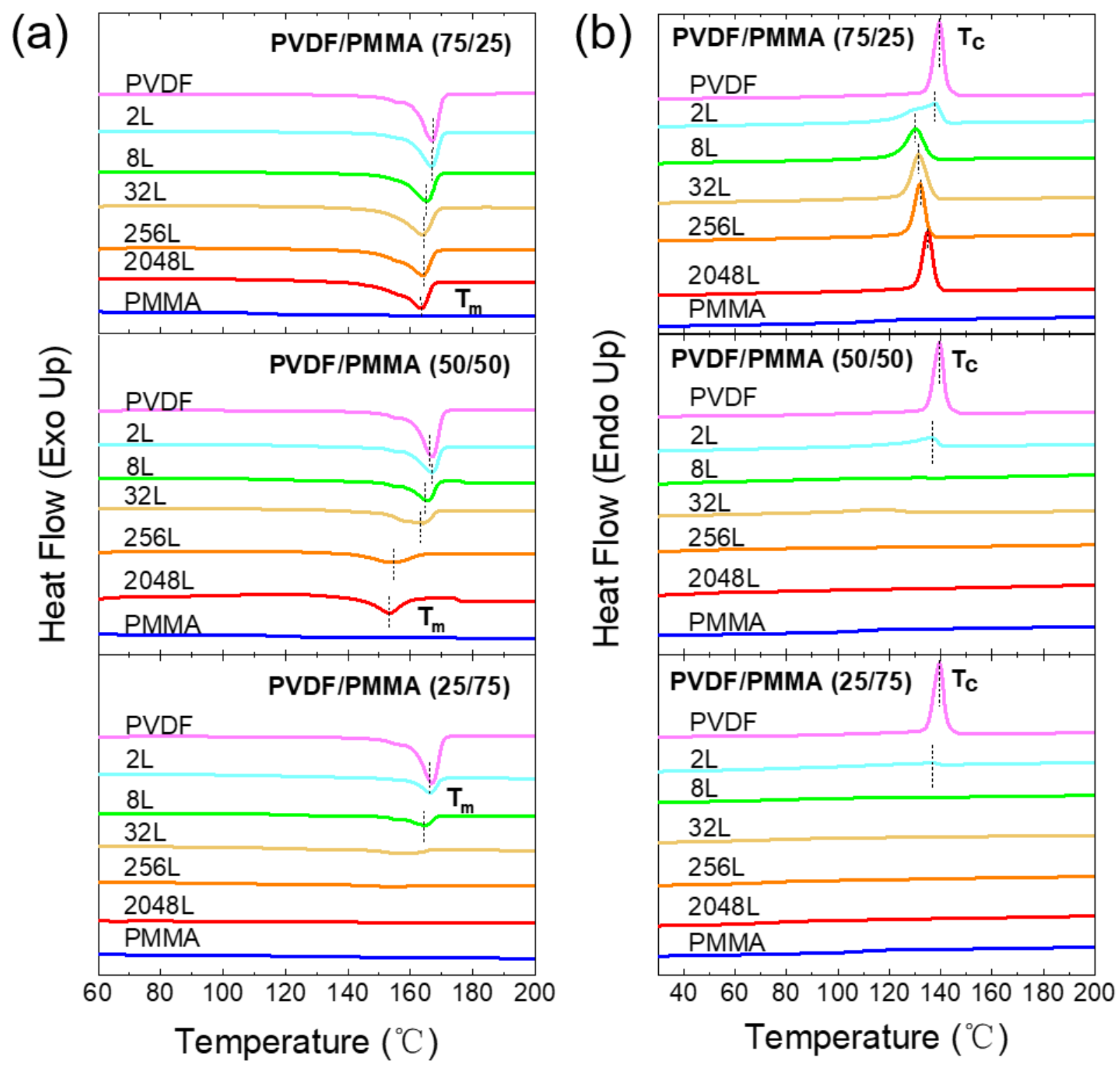

Figure S3. DSC curves of first heating curves (a) and cooling curves (b) for PVDF/PMMA multilayer films with varying compositions. 
Table S2. Characteristic data of microstructure for PVDF/PMMA films.

\begin{tabular}{cccccc}
\hline & Films & $T_{m}\left({ }^{\circ} \mathrm{C}\right)$ & $X_{c}(\%)$ & $L_{c}(\mathrm{~nm})$ & $L_{w}(\mathrm{~nm})$ \\
\hline \multirow{3}{*}{$2 \mathrm{~L}$} & PVDF/PMMA (75/25) & 166.79 & 49.67 & 8.12 & 9.65 \\
& PVDF/PMMA (50/50) & 166.98 & 52.69 & 8.15 & 10.05 \\
& PVDF/PMMA (25/75) & 166.46 & 23.46 & 8.05 & 9.98 \\
\multirow{3}{*}{$8 \mathrm{~L}$} & PVDF/PMMA (75/25) & 165.39 & 44.13 & 7.86 & 9.84 \\
& PVDF/PMMA (50/50) & 165.57 & 41.63 & 7.89 & 10.25 \\
& PVDF/PMMA (25/75) & 164.87 & 20.15 & 7.77 & 10.43 \\
\multirow{3}{*}{$32 \mathrm{~L}$} & PVDF/PMMA (75/25) & 163.92 & 47.22 & 7.61 & 11.24 \\
& PVDF/PMMA (50/50) & 164.19 & 31.41 & 7.66 & 12.41 \\
& PVDF/PMMA (25/75) & 163.92 & 47.22 & 7.61 & 11.24 \\
& PVDF/PMMA (75/25) & 164.02 & 43.95 & 7.63 & 13.29 \\
& PVDF/PMMA (50/50) & 154.95 & 29.30 & 6.37 & 14.20 \\
& PVDF/PMMA (25/75) & 163.92 & 47.22 & 7.61 & 11.24 \\
& PVDF/PMMA (75/25) & 163.50 & 47.26 & 7.54 & 13.10 \\
& PVDF/PMMA (50/50) & 153.64 & 18.00 & 6.22 & 14.92 \\
& PVDF/PMMA (25/75) & - & - & - & 14.61 \\
& pure PVDF & 168.21 & 50.56 & 8.39 & 10.56 \\
& pure PMMA & - & - & - & - \\
\hline
\end{tabular}

In Table S2, the average crystalline lamella thickness $L_{\mathrm{c}}$ for PVDF in all films was determined from the melting temperature $T_{m}$ in the first DSC heating run:

$$
T_{m}=T_{m}^{0}\left(1-\frac{2 \sigma_{e}}{\Delta H_{m}^{0}} \frac{1}{L_{c}}\right)
$$

where $T_{m}^{0}$ is the melting temperature of the infinite thick crystals (i.e., $483.2 \mathrm{~K}$ ) for PVDF; ${ }^{[1]} \sigma_{e}$ is the surface free energy of PVDF $\alpha$-crystals, which is around $38.0 \mathrm{dyn} / \mathrm{cm} .{ }^{[2]}$ 


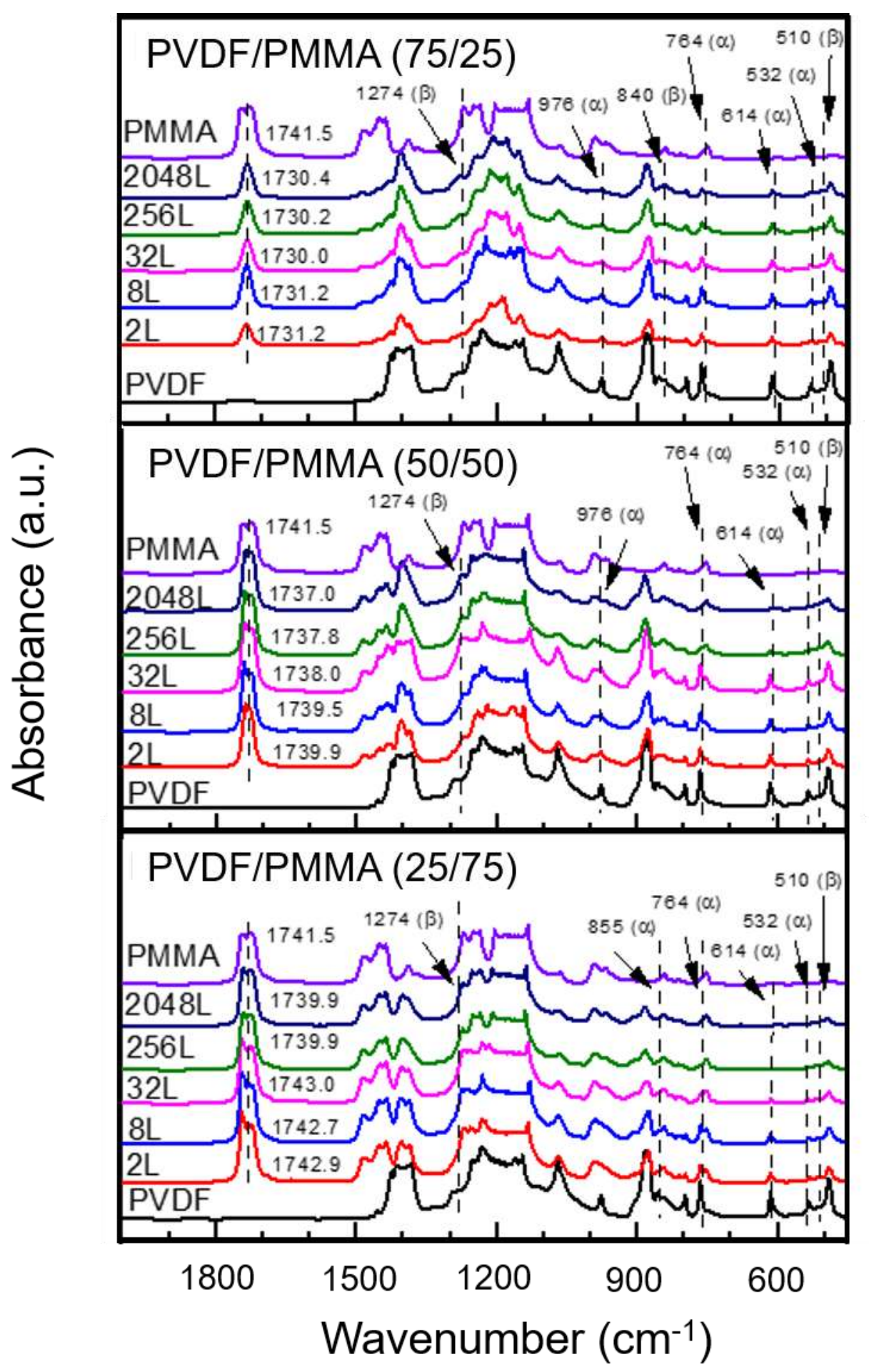

Figure S4. FTIR spectra of PVDF/PMMA multilayer films.

FTIR spectra for PVDF/PMMA films with different compositions are shown in Figure S4. The infrared curve of the sample generally has absorption bands at 489, 532, 614, 764, 795 and $976 \mathrm{~cm}^{-1}$, which correspond to the characteristic spectrum of the $\alpha$ phase crystals of PVDF. As the thickness of the single layer film decreases, the absorption peak of the curve at the above peak position gradually 
decreases, which indicates that the total amount of $\alpha$ crystals decreases. Meanwhile, absorption bands at $510 \mathrm{~cm}^{-1}$ and $1274 \mathrm{~cm}^{-1}$ emerge with PVDF/PMMA multilayer film, which are attributed to $\beta$-phase crystals of PVDF. Also, there is a peak at $840 \mathrm{~cm}^{-1}$ in the PVDF content is $75 \%$, which corresponds to $\beta$-phase.
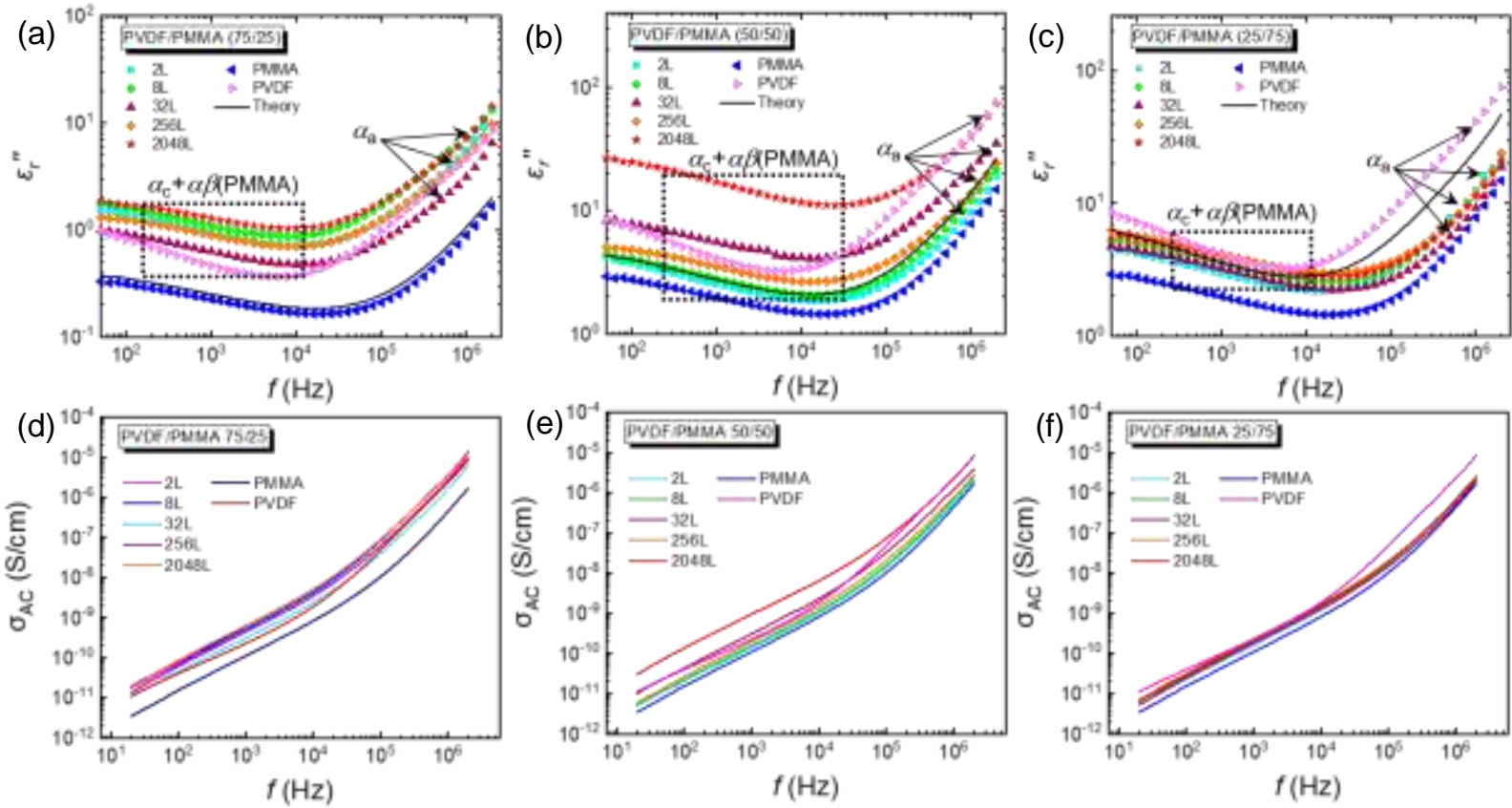

Figure S5. Comparison of imaginary relative permittivity $(\mathrm{a}-\mathrm{c})$ and alternating current conductivity $(\mathrm{d}-\mathrm{f})$ as a function of frequency for PVDF/PMMA films with various compositions. Solid lines in (ac) are theoretical predictions.

\section{References}

[1] Nakagawa, K.; Ishida, Y. Annealing Effects in Poly(vinylidene fluoride) as Revealed by Specific Volume Measurements, Differential Scanning Calorimetry, and Electron Microscopy, J. Polym. Sci., Part B: Polym. Phys. 1973, 11, (11), 2153-2171.

[2] Patki, R.; Mezghani, K.; Phillips, P. J., Crystallization Kinetics of Polymers. In Physical Properties of Polymers Handbook, Mark, J. E., Ed. Springer: New York, 2007; pp 625-640. 